\title{
VELOCITY-BASED MODELING OF THE THERMAL LOAD FOR A FORMULA SAE'S DISK BRAKE SIMULATION
}

\author{
L. F. Bez, \\ M. C. Redin, \\ and L. J. Rodrigues \\ Universidade Federal do Rio Grande do Sul \\ Programa de Pós-graduação em Engenharia \\ Mecânica \\ Porto Alegre, RS, Brasil \\ CEP 90050-170 \\ luiz.bez@ufrgs.br \\ mateus.redin@ufrgs.br \\ leticia.jenisch@mecanica.ufrgs.br \\ ABSTRACT \\ This paper proposes a methodology for the estimation of a disk brake's \\ thermal load based on its vehicle's velocity, where this thermal load serves \\ as an input for a numerical simulation. The load is estimated through a \\ balance between variation in the mechanical energy of the vehicle and the \\ energy dissipated via aerodynamic and rolling drag forces. The RS Racing \\ UFRGS team provided the vehicle's data and geometry, and the velocity \\ data was taken from a real endurance competition. The thermal load thus \\ calculated is then used as input for a $3 \mathrm{D}$ transient finite element model \\ containing the disk and the wheel hub. The results are consistent with what \\ is expected by the RS Racing UFRGS team. Based on the results of the 3D \\ transient model, two more simplified analysis are viable: one in permanent \\ regime, which achieves a temperature distribution within the oscillation \\ presented on the transient model; and also a 2D analysis which can be made \\ by the replacement of the wheel hub with an equivalent global heat transfer \\ coefficient. \\ Received: February 24, 2019 \\ Revised: March 18, 2019 \\ Accepted: March 30, 2019 \\ Keywords: disk brake; heat diffusion; FEM
}

\section{NOMENCLATURE}

a acceleration, $\mathrm{m} / \mathrm{s}^{2}$

$\mathrm{A}_{\mathrm{f}}$ the vehicle's projected frontal area, $\mathrm{m}^{2}$

c rolling friction coefficient

$\mathrm{C}_{\mathrm{D}} \quad$ drag coefficient

$\mathrm{c}_{\mathrm{P}} \quad$ specific heat capacity, $\mathrm{J} /(\mathrm{kg} \mathrm{K})$

$\mathrm{f}$ fraction of the thermal load dissipated at the disk

h convection coefficient, $\mathrm{W} /\left(\mathrm{m}^{2} \mathrm{~K}\right)$

$\mathrm{k}$ thermal conductivity, $\mathrm{W} /(\mathrm{m} \mathrm{K})$

M mass, kg

$\mathrm{Nu}$ mean Nusselt's number

$\mathrm{P} \quad$ potency dissipated at the disk, $\mathrm{W}$

Pr Prandtl's number

$\mathrm{R}$ disk's radius, $\mathrm{m}$

$\mathrm{Re}_{\omega}$ Reynolds' number for the disk's angular velocity

$\mathrm{Re}_{\mathrm{v}} \quad$ Reynolds' number for the vehicle's velocity

t time, $\mathrm{s}$

T temperature, ${ }^{\circ} \mathrm{C}$

$\mathrm{U}_{\text {hub }}$ global heat transfer coefficient relating to the wheel hub

v velocity, $\mathrm{m} / \mathrm{s}$

W vehicle's weight, $\mathrm{N}$

\section{Greek symbols}

$\rho \quad$ specific mass, $\mathrm{kg} / \mathrm{m}^{3}$

$\lambda$ fraction of the thermal load transmitted to the brake pad

v kinematic viscosity, $\mathrm{m}^{2} / \mathrm{s}$

$\omega$ angular velocity, $\mathrm{rad} / \mathrm{s}$

\section{INTRODUCTION}

This work lives in the context of the Formula SAE competition, with its demands both practical and theoretical. The most demanding part of the competition, regarding the disk brake heating, is the endurance test; therefore, the disk must be designed to sustain the loads, both thermal and mechanical during that test. Additionally, the stress is strongly dependent on the temperature field, making even more important its correct estimation.

The material being homogeneous and well modeled by classical means, the difficulty arises on the estimation of the boundary conditions - both the convection coefficients and the thermal load. This paper aims to propose a methodology for the realistic estimation of the thermal load for the disk's thermal analysis, based on the vehicle's velocity during an endurance test.

\section{METHODOLOGY}

The physics of this disk's thermal analysis can be modeled by the heat equation, taking into account that there is no heat source on the domain, and the material is homogeneous and isotropic.

$$
\rho \mathrm{c}_{\mathrm{p}} \frac{\partial \mathrm{T}}{\partial \mathrm{t}}=\mathrm{k}\left[\frac{\partial^{2} \mathrm{~T}}{\partial \mathrm{x}^{2}}+\frac{\partial^{2} \mathrm{~T}}{\partial \mathrm{y}^{2}}+\frac{\partial^{2} \mathrm{~T}}{\partial \mathrm{z}^{2}}\right]
$$

where $\rho$ is the specific mass, $\mathrm{kg} / \mathrm{m}^{3} ; \mathrm{c}_{\mathrm{P}}$ is the specific 
heat capacity, $\mathrm{J} /(\mathrm{kg} \mathrm{K}) ; \mathrm{k}$ is the thermal conductivity, in $\mathrm{W} /(\mathrm{m} \mathrm{K})$; $\mathrm{T}$ is the temperature, ${ }^{\circ} \mathrm{C}$; $\mathrm{t}$ is time, $\mathrm{s}$; and $\mathrm{x}, \mathrm{y}$, and $\mathrm{z}$ are the spatial coordinates, $\mathrm{m}$.

The boundary conditions are nonlinear due to radiation loss and of third species throughout the entirety of the disk's surface. In addition, on the surface where the break pad acts we have a prescribed heat flux entering the disk.

The Table 1 contains the material and vehicle's data utilized in this work.

Table 1. Material and vehicle data.

\begin{tabular}{|c|c|}
\hline Disk properties & Value \\
\hline Specific mass & $7870 \mathrm{~kg} / \mathrm{m}^{3 \mathrm{a}}$ \\
\hline Thermal conductivity & $51.9 \mathrm{~W} /(\mathrm{m} \mathrm{K})^{2}$ \\
\hline Specific heat capacity & $519 \mathrm{~J} /(\mathrm{kg} \mathrm{K})^{\mathrm{a}}$ \\
\hline Wheel hub properties & Value \\
\hline Specific mass & $2810 \mathrm{~kg} / \mathrm{m}^{3 \mathrm{~b}}$ \\
\hline Thermal conductivity & $130 \mathrm{~W} /\left(\mathrm{m} \mathrm{K}^{\mathrm{b}}\right)^{\mathrm{b}}$ \\
\hline Specific heat capacity & $960 \mathrm{~J} /(\mathrm{kg} \mathrm{K})^{\mathrm{b}}$ \\
\hline Air properties & Value \\
\hline Kinematic viscosity & $2.09 \mathrm{e}-5 \mathrm{~m}^{2} / \mathrm{s}^{\mathrm{c}}$ \\
\hline Specific mass & $1.25 \mathrm{~kg} / \mathrm{m}^{3 \mathrm{c}}$ \\
\hline Thermal conductivity & $0.03 \mathrm{~W} /(\mathrm{m} \mathrm{K})^{\mathrm{c}}$ \\
\hline Vehicle parameters & Value \\
\hline Mass & $330 \mathrm{~kg}$ \\
\hline Wheel outer radius & $252 \mathrm{~mm}$ \\
\hline Projected frontal area & $0.87 \mathrm{~m}^{2}$ \\
\hline Drag coefficient & 0.609 \\
\hline
\end{tabular}

The following subsections explain, respectively, how the boundary conditions for the heat loss were calculated, how the heat entering the disk was calculated, and finally which were the numerical parameters used to solve the equation.

\section{Heat Loss Estimation}

The disk loses heat due to conduction to the wheel hub, and convection and radiation at its surface. The conduction loss was initially resolved by simulating the adjacent wheel hub with a finite element model (FEM).

The radiation losses were considered as exchange with surroundings with an emissivity factor of 0.85 and surroundings' temperature of $25^{\circ} \mathrm{C}$.

The convection coefficient was estimated via the correlations proposed by (aus der Wiesche and Helcig, 2016), for a disk spinning in its own axis and subject to a parallel flow. The correlation for the mean Nusselt number $\mathrm{Nu}$, considering $\mathrm{Pr}=0.707$ is shown below.

$$
\mathrm{Nu}=\left[\left(0.33 \operatorname{Re}_{\omega}^{0.5}\right)^{2}+\left(0.033 \operatorname{Re}_{\omega}^{0.8}\right)^{2}\right]^{0.5}
$$

where $\operatorname{Re}_{\omega}$ is the Reynolds number relative to the rotational velocity of the disc, and $\mathrm{Re}_{\mathrm{v}}$ is the Reynolds number relative to the velocity of the parallel flow.

$$
\begin{aligned}
& \operatorname{Re}_{\omega}=\frac{\omega \mathrm{R}^{2}}{v} \\
& \operatorname{Re}_{\mathrm{v}}=\frac{\mathrm{vR}}{v}
\end{aligned}
$$

In the two Reynolds numbers defined in Eq. (3) and (4), $\mathrm{R}$ is the disk's radius, $\mathrm{m}$; $\omega$ is its angular velocity, in radians; $\mathrm{v}$ is the vehicle's velocity, in $\mathrm{m} / \mathrm{s}$; and $v$ is the kinematic viscosity, $\mathrm{m}^{2} / \mathrm{s}$.

The Reynolds numbers, and consequently the mean Nusselt number, vary along the circuit's lap, according to the data collected form the LSU Tiger Racing team (https://www.youtube.com/watch?v= LxnKVBsBap, retrieved April 8, 2018). The resulting convection coefficient during one lap is given by the graph in Fig. (1).

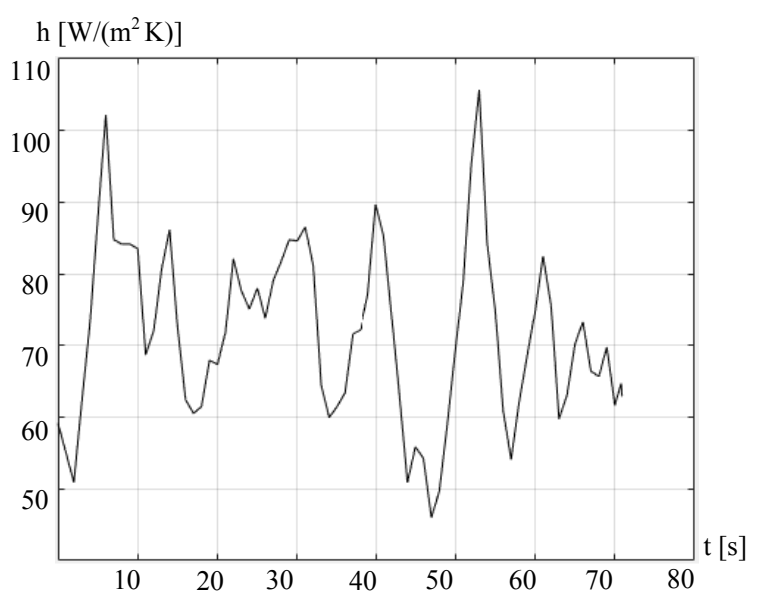

Figure 1. Convection coefficient in one lap of the endurance test.

\section{Heat Load Estimation}

An endurance circuit is meant to test the vehicle's limits; it contains rough terrain and a quick succession of acceleration and deceleration. Every time the vehicle decelerates some energy is dissipated at the disks.

A hypothesis was made that the mechanical energy lost by the vehicle is lost either to heat on the disk brake, or to aerodynamic and rolling drag. This energy is not equally divided among the disks, with $35 \%$ going to each frontal disk and $15 \%$ to each rear disk (de Abreu, 2013). This paper presents results for a frontal disk, because it's the critical one. Also, some of the heat dissipated at the interface between the disk and the break pad goes to the pad. 


$$
\mathrm{P}=\mathrm{f}(1-\lambda) \mathrm{v}\left(\mathrm{Ma}-\frac{1}{2} \mathrm{C}_{\mathrm{D}} \rho \mathrm{A}_{f} \mathrm{v}^{2}-\mathrm{cW}\right)
$$

The potency $\mathrm{P}$ entering the disk is given by Eq. (5), where $f$ is the energy fraction dissipated in the disk -0.35 in this case; $\lambda$ is the fraction of energy transmitted to the pad (Deressa, 2013) - 0.02 in this case; $\mathrm{M}$ is the vehicle's mass, $\mathrm{kg}$; $\mathrm{a}$ is its acceleration, $\mathrm{m} / \mathrm{s}^{2} ; \mathrm{C}_{\mathrm{D}}$ is its drag coefficient, obtained experimenttally by the RS Racing UFRGS team; $A_{f}$ is the vehicle's projected frontal area, $\mathrm{m}^{2}$; $\mathrm{c}$ is the rolling coefficient (https://www.engineeringtoolbox.com/rol ling-friction-resistance-d_1303.html, Retrieved April $8,2018)$; and $\mathrm{W}$ is the vehicle's weight, $\mathrm{N}$.

This equation is valid if $\mathrm{a}$ is negative. If either a is positive or the resulting $\mathrm{P}$ is negative, the potency dissipated at the disks is considered to be zero.

In the absence of measurements for an endurance test by RS Racing UFRGS, the velocity data was collected from an endurance race from FSAE Michigan 2015, published by the LSU Tiger Racing team (https://www.youtube.com/watch?v= LxnKVBsBap, retrieved April 8, 2018). This velocity data has resolution of $0.1 \mathrm{~s}$. The acceleration was estimated via numerical derivation. The resulting heat entering the disks during one lap of the circuit is presented in Fig (2).

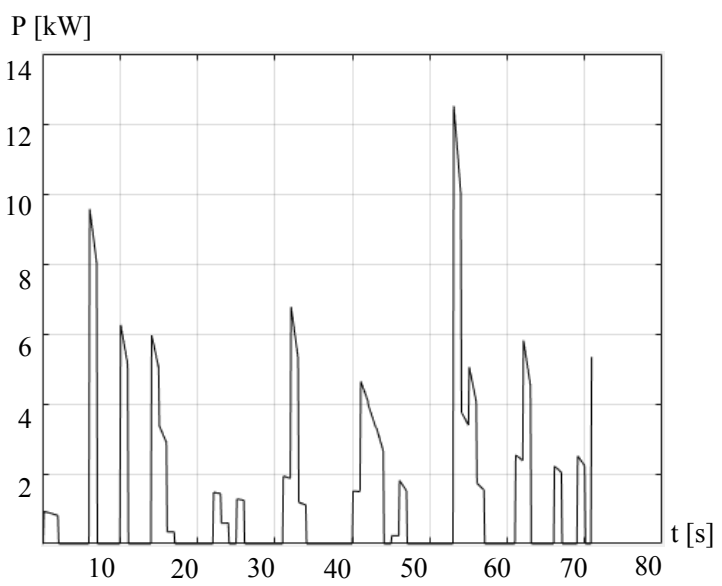

Figure 2. Heat dissipated at the disk in one lap of the endurance test, given by Eq. (1).

\section{Geometry and Numerical Model}

The simulated geometry is presented in Fig. (3). The region in red is the wheel hub and a small portion of the frontal axis of the vehicle, where heat is transmitted from the disk. The disk is composed by the gray, yellow, and blue areas. The blue area represents the shape of the brake pad and the yellow area represents the band where the pad acts on the disk.

The convection and radiation boundary conditions were applied normally in all regions, except where the pad slides along the disk. In those areas the coefficients were penalized in proportion to the area of the band covered by the pad and a homogeneous coefficient was applied therein.

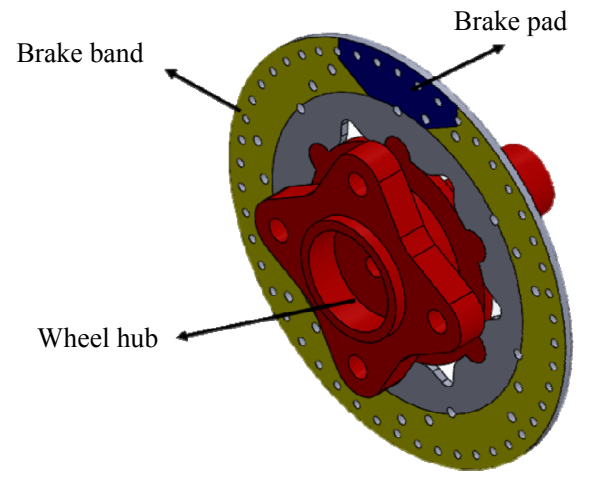

Figure 3. Geometry simulated on the 3D model. In blue is the break pad area, in yellow the break band, and in red the wheel hub.

The head load was applied as a prescribed heat flux on the braking region - yellow and blue in Fig. (3) - with the potency P on Fig. (2) being equally divided between the friction areas on both sides of the disk.

The Eq. (1) was solved using FEM, with the Galerkin formulation. Regarding the spatial discretization, a uniform mesh was utilized with 20node hexahedral elements with tri-quadratic interpolation functions. The final mesh used had a $2 \mathrm{~mm}$ edge size and the time step was of 0.1 second, the same as the resolution of the velocity data. The results for the maximum temperature had a maximum deviation of $0.25 \%$ in relation to a mesh with edge size two times smaller and time step also two times smaller.

\section{RESULTS AND DISCUSSION}

This section is divided in three parts: beginning with the 3D transient model; following with the 3D model in permanent regime; and ending with a discussion on how to go from a 3D to a 2D model, by replacing the wheel hub with an equivalent heat transfer coefficient.

In all FEM analysis the material simulated was steel AISI 1020 for the disc and aluminum 7075-T6 for the wheel hub. The used properties for these materials, along with the relevant properties of the air, and vehicle data are presented on the following table.

The physics of this disk's thermal analysis can be modeled by the heat equation, Eq. (1), taking into account that there is no heat source on the domain, and the material is homogeneous.

\section{D Transient Model}

The 3D model was fed with the heat load as defined on the methodology section. Due to the 
nature of the endurance trial, and of the thermal load, is expected that the temperature of the disc will initially increase and after a few laps it will oscillate as following laps go by.

Five laps - 360 seconds - on the simulated endurance path were enough to reach said stability. The temperatures on the disk oscillated between 250 and $320^{\circ} \mathrm{C}$, with less than $1 \%$ of difference between temperature extremes from one lap to the next.

The cyclical behavior of the maximum temperature at the disk is presented on Fig. (4). The characteristics of the cycle are linked to the characteristics of the endurance circuit.

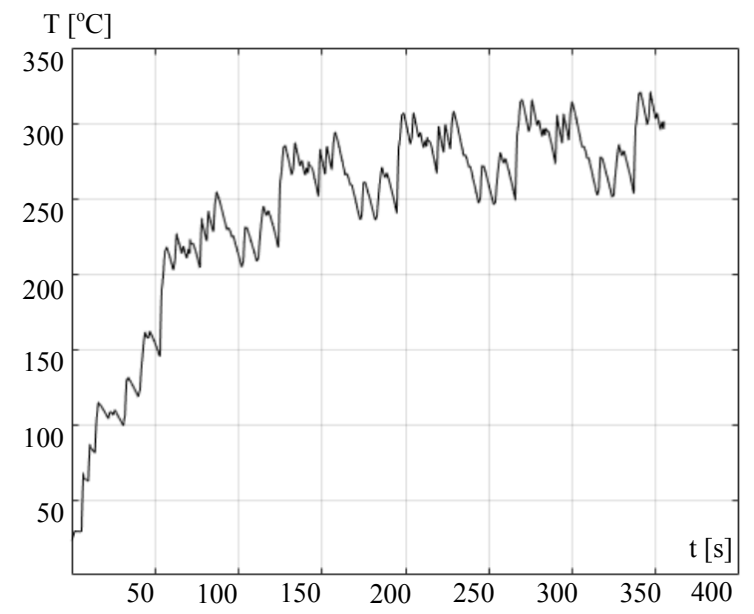

Figure 4. Maximum temperature on the disk, during 5 laps of the endurance test.

On Fig. (5) we can see the temperature distribution along the disk, both in full view and in a detailed one. There is an important spatial gradient on the disk which suggests that thermal stress will be an important component of the disk's mechanical design, in accordance with the literature (Brezolin, 2007; Infantini, 2008).

Since this 3D transient model captures the oscillatory behavior of the temperatures, its results could be used for the estimation of cyclical thermal tensions and a possible scenario of mechanical fatigue on the disk. The mechanical analysis of the disk was not pursued on this paper.

The main drawback of this model is the fact that it is very time consuming in relation to the other presented below.

\section{Permanent Regime Simulation}

From the values of heat load and convection coefficients along a lap - Figs. (1) and (2) - we calculated their average values aiming to feed them on a $3 \mathrm{D}$ permanent regime model. The maximum temperature in that permanent regime model was found to be $297.7^{\circ} \mathrm{C}$, value that lies within the oscillatory interval presented by the transient model.

The simulation of the problem in permanent regime is considerably faster that the transient one (the latter uses 360 time steps), therefore it could be useful for early stages of design for a particular disk geometry.

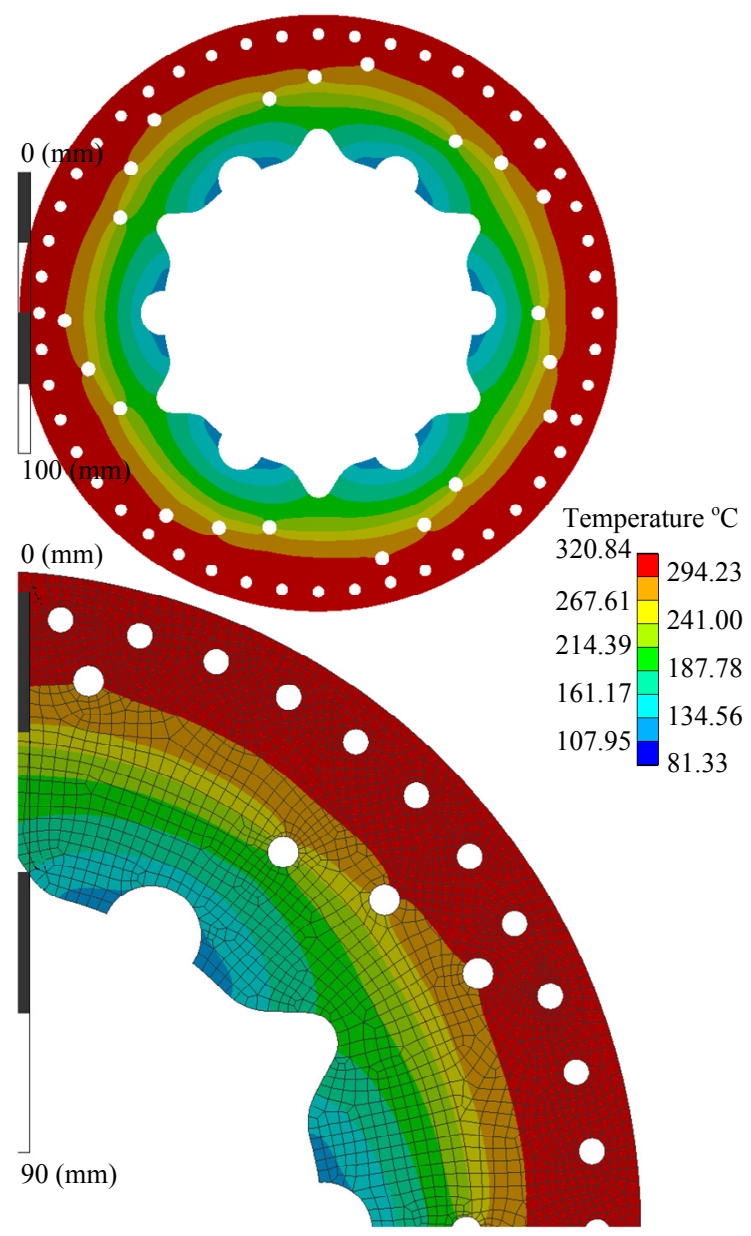

Figure 5. Temperature contour plot for the entire disk (top) and a detail (bottom).

\section{Replacing the Wheel Hub with a Global Heat Transfer Coefficient}

The disk brake is in essence a plate, with one of its dimensions much smaller than the other. That suggests the viability of a 2D model that is lumped on the thickness.

The temperature field along the disk's thickness is of the order of $2^{\circ} \mathrm{C}$, or less than $1 \%$ of the excess of temperature present between the disk and the surroundings. Therefore, the disk may be solved as a 2D problem, with a modification of the differential equation. If the model is $2 \mathrm{D}$, the heat load and the convection on the surface of the disk would be mathematically modeled as a time dependent source term, and as a time and temperature dependent sink term, respectively. They would form a non-linear body force term that should pose no major problems even for a classical numerical solver.

While the disk may be modeled as a $2 \mathrm{D}$ entity, 
the wheel hub cannot. Its geometry is much more complex, there is no dominant direction for it and the gradients along it are of the same order of magnitude in every direction, albeit overall smaller than the gradients on the disk. The wheel hub also presents smaller temperatures in general, which means that the radiation heat transfer - which represents around 10\% of the heat lost by the disk - will be less important on the wheel hub. Since convection and conduction are the dominant heat transfer mechanisms on the hub, the heat transfer through it can be simplified as a linear phenomenon, and the entire hub could be replaced by a global heat transfer coefficient $U_{\text {hub }}$ applied to the areas where the disk and the hub meet.

The calculated $\mathrm{U}_{\text {hub }}$ for this problem was $1367 \mathrm{~W} /\left(\mathrm{m}^{2} \mathrm{~K}\right)$, or an equivalent thermal resistance of $0.65^{\circ} \mathrm{C} / \mathrm{W}$. The heat rate transferred to the hub is, on average, $212.7 \mathrm{~W}$, and representing $17.5 \%$ of the total heat load. When these values are applied as boundary conditions where the disk meets the hub (with the latter suppressed from the model) no significant differences were observed on the disk's temperature field.

(Iombriller, 2002) suggests that the heat transmitted from the disk to the wheel hub, for a vehicle of this size and speed should be of $22 \%$ of the heat load on the disk. However, the vehicles they studied were significantly different from ours, in size, velocity, and usage, which may explain the difference between the heat rate transmitted to the hub that they suggest versus the one found in our simulation.

\section{CONCLUSIONS}

When we are talking about vehicles designed for competition, as is the case of the one studied in this paper, it is advantageous that its components be optimized in order to gain an edge on the competition. The optimized designs of these components usually rely on numerical simulations, since they are considerably cheaper and faster than the experimental alternative. In accordance to that, a reliable and realistic numerical model is essential for the design process.

In this paper a methodology was presented that intakes information about the vehicle's speed in an easy way to measure (using only the navigational system already present on the car) and uses it to estimate a realistic thermal load for the disk brakes.

The 3D transient model presented results that are consistent with the RS Racing UFRGS team's experience and that had enough resolution for the calculation of thermal stresses, if needed.

The permanent regime model proposed was successful in predicting an average temperature for the disk, useful for quick design analysis and presenting temperature fields consistent with the full 3D transient model.

The substitution of the wheel hub by an equivalent global heat transfer coefficient proved to be successful and consistent with the results of the full geometry with the hub being simulated. This substitution, together with the low temperature gradients along the disk thickness, could allow for a 2D lumped model of the disk. This simplified model would reduce even more the necessary computational effort of the analysis. As a continuance of this work we suggest a comparative test between a $2 \mathrm{D}$ lumped model and the 3D one, both in transient and permanent regime.

Finally, in this paper we focused on a realistic estimation of the thermal load. The same could be done for the convection coefficient. The correlations used and the application of an average convection coefficient on the disk are simplifying hypothesis that may skew the temperature results.

\section{ACKNOWLEDGEMENTS}

This work sprung from a collaboration between the RS Racing UFRGS team and OTMZA Assessoria em Engenharia, the junior enterprise of the Mechanical Engineering course at UFRGS. They provided the data and the numerical resources needed for this paper.

The first author would also like to thank PROMEC/UFRGS and CNPq for the master's scholarship he received during the production of this paper.

\section{REFERENCES}

aus der Wiesche, S., and Helcig, C., 2016, Convective Heat Transfer from Rotating Disks Subjected to Streams of Air, 1st Edition, Springer.

Brezolin, A., 2007, Estudo de Geração de Trincas Térmicas em Discos de Freios de Veículos Comerciais, Master Thesis, Universidade de Caxias do Sul, Caxias do Sul, RS. (in Portuguese)

de Abreu, R. M., 2013, Simulação e Ensaio de Mecanismo de Freio Automotivo, Master Thesis, Universidade Federal de Minas Gerais, Belo Horizonte, MG. (in Portuguese)

Deressa, K. T., 2013, Thermal Stress Analysis of Disc Brake Rotor by Finite Element Method, Master Thesis, Addis Ababa University, Addis Ababa, Ethiopia.

Infantini, M. B., 2008, Variáveis de Desempenho dos Sistemas de Freio, Master Thesis, Universidade Federal do Rio Grande do Sul, Porto Alegre, RS. (in Portuguese)

Iombriller, S. F., 2002, Análise Térmica e Dinâmica do Sistema de Freio a Disco de Veículos Comerciais Pesados, Doctoral Thesis, Universidade de São Paulo, São Carlos, SP. (in Portuguese)

Limpert, R., 1999, Brake Design and Safety, 2nd Edition, Society of Automotive Engineers. 